\title{
Nutrition for Acute Exercise-Induced Injuries
}

\author{
Kevin D. Tipton \\ Sports, Health and Exercise Sciences Research Group, University of Stirling, Stirling, UK
}

\author{
Key Words \\ Immobilization - Muscle atrophy $\cdot$ Muscle protein \\ synthesis · Inflammation • Omega-3 fatty acids · Protein • \\ Energy balance
}

\begin{abstract}
Background/Aims: Injuries are an unavoidable aspect of participation in physical activity. Little information about nutritional support for injuries exists. Review: Immediately following injury, wound healing begins with an inflammatory response. Excessive anti-inflammatory measures may impair recovery. Many injuries result in limb immobilization. Immobilization results in muscle loss due to increased periods of negative muscle protein balance. Oxidative capacity of muscle is also decreased. Nutrient and energy deficiencies should be avoided. Energy expenditure may be reduced during immobilization, but inflammation, wound healing and the energy cost of ambulation limit the reduction of energy expenditure. There is little rationale for increasing protein intake during immobilization. There is a theoretical rationale for leucine and omega-3 fatty acid supplementation to help reduce muscle atrophy. During rehabilitation and recovery from immobilization, increased activity, in particular resistance exercise will increase muscle protein synthesis and restore sensitivity to anabolic stimuli. Ample, but not excessive, protein and energy must be consumed to support muscle growth. During rehabilitation and recovery, nutritional needs are very much like those for any athlete desiring mus-
\end{abstract}

cle growth. Conclusion: Nutrition is important for optimal wound healing. The most important consideration is to avoid malnutrition and to apply a risk/benefit approach.

Copyright $\odot 2011$ S. Karger AG, Basel

\section{Introduction}

Injuries are an unfortunate, but unavoidable, aspect of participation in physical activity - regardless of the level of participation. An injury may strike any exerciser from those exercising for health and enjoyment up to the elite athlete. The negative aspects of injuries, particularly if it is prolonged or results in immobilization of a limb, are obvious. Injuries resulting from physical activity almost certainly will lead to decreased activity and loss of muscle mass, strength and function. Minimizing the impact of the injury and enhancing recovery from the injury are crucial for athletes, as well as other exercisers.

Injured exercisers commonly practice many modalities in an attempt to enhance healing and return to activity. Rest, ice, massage, heat, electrical stimulation, acupuncture and many others are used. One aspect of recovery that is often overlooked or underappreciated, at least from a research perspective, is nutrition. Much has been written about nutrition for sports and exercise injuries, but surprisingly little is based on research directly investigating these issues.

\section{KARGER \\ Fax +4161306 1234 \\ E-Mail karger@karger.ch}

www.karger.com
(C) 2011 S. Karger AG, Basel

$0250-6807 / 10 / 0576-0043 \$ 26.00 / 0$

Accessible online at:

www.karger.com/anm
Kevin Tipton

Sports Studies

University of Stirling

Stirling FK9 4LA (UK)

Tel. +44 178646 7816, Fax + 44178646 6477, E-Mail k.d.tipton@ stir.ac.uk 
Given the relative paucity of data from studies assessing the response to and recovery from exercise-related injuries, an attempt will be made to critically evaluate information from other models in the context of injury to athletes and exercisers. For example, evidence from the literature associated with wound healing, trauma, bed rest, surgery and other situations may be applicable to exercise-induced injuries. In addition, the eccentric, muscle damage model has often been touted as representative of injury and there is a fair bit of data concerning the impact of nutrition using that model. Unfortunately, much of it is poorly controlled, so conclusions must be made cautiously.

The focus of this review will be to critically evaluate information - from studies directly measuring the response to injury as well as information from other models - concerning nutritional interventions applicable to exercise-induced injuries. Particular focus will be put on the metabolic and functional consequences of limb immobility and the nutritional interventions that may ameliorate these consequences and/or enhance recovery from those injuries. The discussion primarily will be on acute, traumatic injuries, rather than chronic overuse injuries. In particular, attention will be given to problems associated with limb immobilization associated with injuries.

\section{Nutritional Status}

There is no question that poor nutritional status will impede healing and recovery from injury. In particular, protein and energy malnutrition exacerbates the inflammatory response and slows wound healing $[1,2]$. The focus of this review will primarily be on healthy exercisers and athletes. Thus, malnourishment is unlikely to be an issue in most cases. In that context, this review will only refer to malnourishment in particular situations in which energy, protein and micronutrient intake may be poor prior to the injury.

\section{Stages of Injury}

Most exercise-induced injuries we will consider in this review, at least those that are more severe, can be considered to have two main stages, either of which may be influenced by nutrition. These stages may be further divided into various phases in regard to particular aspects of the recovery from injury.
The first is the immobilization/atrophy stage. The type and severity of the injury will determine the length of time for immobilization - lasting from a few days up to several months and perhaps consisting of partial to full immobility of the injured limb. During this time, metabolic changes in the tissues resulting from disuse lead to loss of strength and function [3]. The loss of muscle that leads to these functional problems is well documented, but other tissues, such as tendons, also may be impacted [4].

The second stage follows the return of mobility. Rehabilitation and increased activity of the injured limb lead to recovery of muscle hypertrophy and the return of functionality [3]. Unfortunately, it is very clear that complete recovery of strength and function following injuryinduced immobilization takes much longer than the time it takes to lose them [3]. Nutritional suggestions are often similar for these 2 phases, but there are differences that should be considered.

There are some injury situations in which a third stage may need to be considered. In many circumstances, an athlete or exerciser may be scheduled for surgery sometime in the future. Thus, the time for initiation of the immobility will be known. This knowledge may be used to prepare for the immobility and nutrition may be an important aspect of this preparation. Generally, the nutritional recommendations during this time would be to maximize muscle mass and fitness, so no different than those for any other athlete with similar goals [5-7]. This review will focus on the first 2 stages of injury.

\section{Stage 1: Tissue Repair, Immobilization and Atrophy}

During this stage, there are 2 aspects of the injury to consider. One is healing of the injury itself and the second is any necessary immobilization or reduction in activity that is associated with the injury. Nutrition may have an important influence over both aspects.

\section{Tissue Repair}

Wound healing is a complex process involving many physiological pathways. There is a progression to normal tissue repair that can be considered as 3 main, overlapping phases: inflammation, proliferation and remodelling. A detailed description of these phases is beyond the scope of this review. The interested reader is referred to a number of excellent review papers on this topic $[1,2$, $8-10]$. Repair processes begin within only a few minutes of the injury and continue for days to weeks depending on the type and severity of the injury [8]. 
Immediately following a severe injury, an inflammatory response is initiated. The inflammatory response is necessary for proper healing. This stage may last for a few hours up to several days depending on the injury [9]. Often recommendations are made to decrease or even eliminate the inflammatory response. However, given that inflammation is a critical component of the healing process [9], elimination of the inflammation may not be ideal for optimal recovery. In some very severe injuries, e.g. major burn injury, excessive inflammation may occur, particularly in patients that are otherwise metabolically compromised. However, most exercise-induced injuries, particularly in otherwise healthy exercisers and athletes, would not be severe enough for uncontrolled inflammation to be an issue [9].

The inflammatory response is marked by activation of many processes that result in the initiation of the healing process and eliminate invading microorganisms $[8,11]$. These processes are energy requiring thus energy expenditure increases during wound healing. The exact nature of the inflammatory process and the length of time it lasts depend on the nature of the injury. Both soft tissue and bone injuries result in inflammation to begin the healing process [8].

The proliferative phase is primarily associated with deposition of the collagen matrix for scar formation and proliferation of local fibroblasts [8]. There is an increase in protein synthesis for cell division following which extracellular matrix products are secreted. Granulation, i.e. directed growth of new capillary networks, is followed by contraction of the wound to reduce the size of the injury. Finally, epithelialization for wound closure occur in skin wounds. As with the inflammatory process, all these steps consume energy.

During remodelling, the scar tissue formed as a result of the first 2 phases is broken down and replaced by type I collagen, a much more robust form of collagen [8]. Thus, not only protein synthesis, but also degradation of protein plays an important role. Interestingly, this tissue is laid down upon lines of tension. Thus, the activity pattern during this phase will influence the effectiveness of the repair.

Bone repair is slightly different to soft tissue repair. The initial, inflammatory, phase is similar to soft tissue injury [10]. Osteoblast formation quickly follows the initial injury. Next, a cartilaginous callus is formed to provide initial stabilization of the fracture site [10]. Initially, the callus is incomplete, so soft and rather weak. Collagen synthesis is an important factor during this time. Finally, chondrocytes start to hypertrophy, proteases break down

Nutrition for Acute Exercise-Induced Injuries the collagen of the soft callus and mineralization begins [10]. Angiogenesis then begins the formation of new vasculature, which then infiltrates the new bone. Coordinated osteoclast/osteoblast activity then remodels the bone such that it is the same as the original [10]. As with soft tissue repair, all of these processes require ample energy.

\section{Muscle Atrophy with Immobility}

Many exercise-induced injuries result in the necessity to immobilize a limb or otherwise reduce overall activity. During immobility, the most obvious result is a rapid loss of muscle mass leading to reduced muscle strength and function, particularly in weight-bearing limbs $[3,4,12]$. Muscle protein balance, i.e. the balance between the rate of muscle protein synthesis and muscle protein breakdown, is the metabolic mechanism responsible for changes in muscle mass [13]. Negative net muscle protein balance results when the rate of muscle protein synthesis is exceeded by breakdown. Negative balance over any given time means that muscle protein is reduced resulting in muscle loss [13].

Negative net muscle protein balance with inactivity in humans leading to muscle loss is a decrease in the rate of muscle protein, particularly myofibrillar protein [12], synthesis [14]. Interestingly - perhaps unexpectedly to many [15] - protein breakdown also decreases, at least in humans [14]. The decrease in muscle protein synthesis is greater than the decrease in muscle protein breakdown, thus the muscle is in net negative protein balance. Clearly, nutritional interventions aimed at ameliorating muscle loss during injury-induced immobilization should focus on alleviating, as much as possible, the decrease in muscle protein synthesis such that negative periods of muscle protein balance are minimized.

Loss of muscle strength is not the only detrimental aspect of immobilization for athletes to consider. Recent evidence clearly demonstrates that muscle mitochondrial oxidative function and metabolic flexibility are impaired. Transcriptional downregulation of mitochondrial proteins, decreases in translational signalling pathways involved in mitochondrial biogenesis and declines in mitochondrial enzyme activities all result from immobilization [16]. Some of these changes occur as early as $48 \mathrm{~h}$ following initiation of inactivity. Nearly all aspects of mitochondrial function are impacted [16]. It is well known that inactivity leads to depressed insulin sensitivity [17, 18]. The detrimental impact on glucose action may have much to do with the decreased GLUT4 content in immobilized muscle [19]. Certainly, athletes and exercisers 


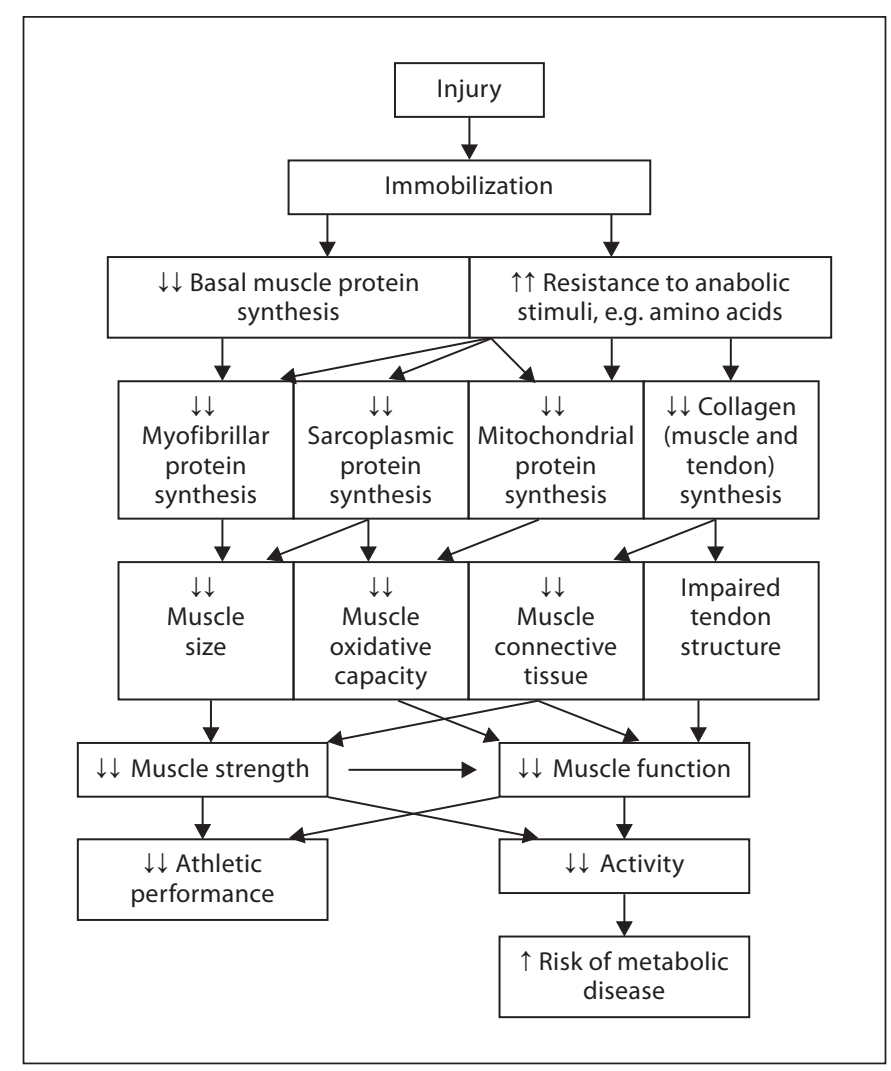

Fig. 1. Flow diagram of the metabolic and functional changes during immobilization due to exercise-induced injury. Decreased basal synthesis of muscle and tendon proteins, as well as decreased stimulation from amino acids leads to a quick and dramatic decrease in muscle size and strength, tendon structure and function.

must consider these adverse changes to muscle oxidative and metabolic function during immobilization.

In addition to decreased muscle protein synthesis with muscle immobility, a potentially more important detrimental change is the reduced response of muscle protein synthesis to nutritional anabolic stimuli. Glover et al. [12] demonstrated that immobility decreases the ability of myofibrillar proteins to respond to amino acids [12]. This situation is termed anabolic resistance. Anabolic resistance to insulin has also been reported $[20,21]$. Thus, muscle may be lost during immobilization through increased negative muscle protein balance mediated by decreased basal levels of muscle protein synthesis, as well as less positive net muscle protein balance due to the decreased response of muscle protein synthesis to nutritional stimuli.

Muscle loss is the obvious focus during disuse stemming from injury. However, bone, tendons and ligaments are important for exercise performance and are also impacted negatively by immobilization [4]. The connective tissue protein, collagen, is the primary component of tendons and ligaments. Decreased tendon collagen synthesis from immobilization results in changes in tendon mechanical properties important for proper tendon function [4]. However, other aspects of tendon, bone and ligament healing in relation to collagen remain to be determined. Declines in tendon function are perhaps an underappreciated detrimental aspect of limb immobilization with injury. These processes are illustrated in figure 1.

\section{Nutrition Support for Tissue Repair and Atrophy \\ Protein Intake}

Often the first nutritional countermeasure considered for muscle loss and wound healing is increased protein intake. Clearly, insufficient protein intake will impede wound healing and increase inflammation to possibly deleterious levels $[1,2]$. Given that muscle loss results from decreased synthesis of myofibrillar proteins [12] and that the healing processes are heavily reliant on synthesis of collagen and other proteins [8], the importance of protein should be obvious. Protein intake clearly increases muscle protein synthesis, both at rest and following exercise, resulting in positive muscle protein balance [22-25]. However, given the resistance of immobilized muscle to anabolic stimulation by nutrients during immobilization [8], increased protein intake during disuse may not have the impact on maintenance of muscle mass that could be expected from studies in healthy muscle.

Despite the inability of increased protein intake to alleviate muscle loss during immobility due to anabolic resistance, there is an intervention that could - at least potentially - decrease this resistance. Leucine is well known to increase protein synthesis in cell culture and rat studies [26-28]. Whereas leucine intake has been widely claimed to help increase muscle mass during resistance exercise training, the evidence is tenuous and unsubstantiated in human studies [29-31]. However, leucine may help overcome the resistance of muscle protein synthesis to anabolic stimuli. Leucine ingestion ameliorates muscle loss in rats during immobilization [32]. Moreover, studies in elderly humans show that the anabolic signalling pathways in muscle are inhibited, thus reducing protein synthesis [33]. However, the anabolic resistance may be overcome by increasing the leucine content of ingested protein $[34,35]$. To date, no study has specifically examined the impact of ingesting extra leucine with or without pro- 
tein on muscle protein synthesis and muscle loss in immobilized human muscle. However, it is intriguing to consider and should be studied. Of course, the amount of leucine in relation to the protein and other details of such an intervention must be investigated in future studies.

Very little is known about nutritional influences on tendon metabolism in any situation, let alone after injury. Collagen synthesis rates in tendon and muscle do not respond to increased amino acid levels [36], suggesting that protein feeding would have little impact on tendon healing. Bone collagen synthesis, an important aspect of bone healing, on the other hand, does respond to increased amino acid levels [37]. There is evidence that protein supplementation enhances recovery from hip fracture surgery [38-40]. However, these results came from studies in elderly patients, many of whom exhibit protein-energy malnutrition [39]. So, efficacy for young, healthy athletes is still to be determined. Nevertheless, these data suggest that protein feeding may enhance bone formation following injury, albeit at this time only in theory.

Undoubtedly, sufficient protein intake is necessary to support wound and/or fracture healing. However, there does not seem to be much support for increasing protein intake to enhance recovery or to slow muscle loss with immobilization. There is some theoretical rationale for increasing leucine intake, but direct evidence for these injury situations is not forthcoming. Clearly, more research into the optimal protein and amino acid intake during this phase of injury is necessary.

\section{Energy Intake}

An important consideration during injury-induced immobilization is the appropriate energy intake. Recommendations may be considered somewhat counterintuitive. The first impulse of most injured athletes generally is to reduce energy intake. By necessity, the total energy expenditure is likely to decrease during immobility, particularly if the immobilized limb is involved in ambulation. Depending on which limb is immobilized, a substantial decrease in total energy expenditure may develop voluntarily, because exercise is more difficult or less convenient, or by necessity as options are limited [41, 42]. At the very least, forms of exercise that do not involve the immobilized muscles must be engaged. Furthermore, a more subtle reduction may stem from reduced protein turnover [14]. Thus, in order to avoid weight gain, most athletes will naturally decrease energy intake.

There are factors to consider that should impact the magnitude of this necessary reduction. First, it is quite clear that during the healing process, energy expenditure

Nutrition for Acute Exercise-Induced Injuries is increased - particularly early on and if the injury is severe - by up to approximately $20 \%$ [43]. So, whereas overall energy expenditure still may be less than normal, the total likely is not as low as many would at first assume.

Another factor related to energy intake that may need to be considered by many injured athletes is the energy cost of ambulation. If an injury results in the necessity to use crutches, the energy cost is dramatically increased. Ambulation with crutches results in energy expenditures in the range of 2-3 times that of regular walking [41]. Thus, depending on how much crutching is done, energy intake may not need to be dramatically reduced.

The energy intake during immobilization may also have an impact on muscle protein synthesis. Care should be taken to ensure that any decrease in energy intake is not so much that optimal muscle protein synthesis is unsupported. Muscle protein synthesis is an energetically expensive process. It has been estimated that a well-muscled male expends approximately $500 \mathrm{kcal}$ a day on muscle protein synthesis even without considering physical activity [44]. Thus, insufficient energy could inhibit the ability of muscle to synthesize proteins. Pasiakos et al. [45] recently demonstrated that an energy intake of approximately $80 \%$ of requirement for 10 days reduced muscle protein synthesis by $19 \%$. Decreased synthesis is the major contributor to muscle loss [12], thus care should be taken to optimize muscle protein synthesis whenever possible. A small weight gain may be preferable to lack of energy to support proper muscle healing. That decision must be made after careful consultation between the nutritionist, athlete and coach.

\section{Other Nutrients}

Consideration of the intake of other nutrients during this phase of injury must be considered. Again, the most important factor is to avoid nutrient deficiencies. Ample carbohydrate intake to support what training is performed would be critical. There is also evidence that muscle protein synthesis $[46,47]$ and net muscle protein balance [47] during and following exercise may be impaired in muscle with low glycogen levels. Thus, careful consideration of carbohydrate intake is important for an athlete recovering from injury.

Athletes and exercisers must also consider fat intake during injury. As with many other nutrients, there is no reason to suggest an increase in overall intake of fat. However, many athletes may desire a dramatic decrease in fat intake in order to decrease overall energy intake. Too little fat in the diet may lead to deficiencies of essential fatty acids. There is some evidence to suggest that the 
Fig. 2. Flow diagram of the theoretical metabolic and functional changes during immobilization. Leucine may be able to overcome the resistance to the anabolic stimulus of amino acids, thus ameliorating the loss of muscle mass and function.

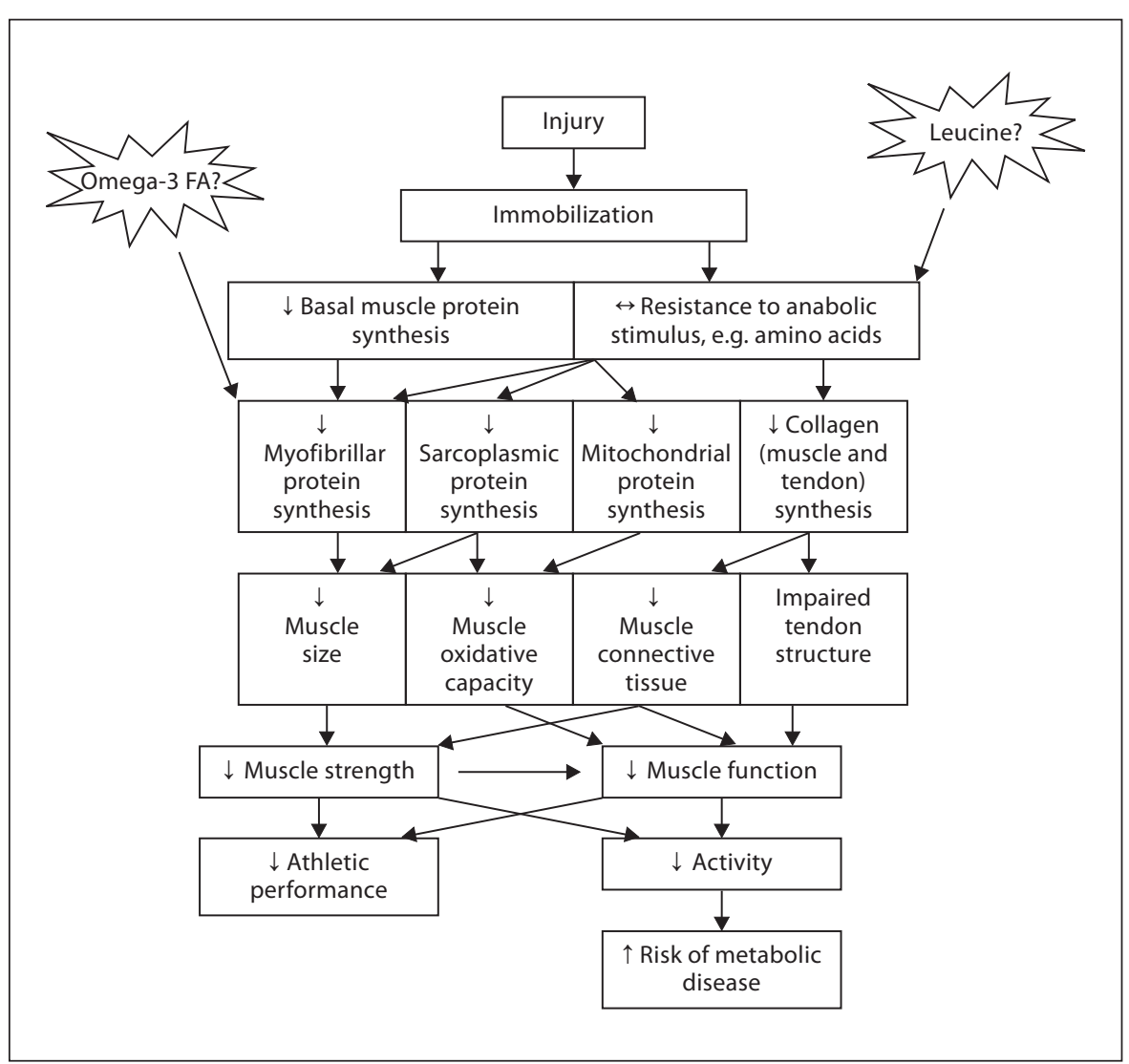

demand for essential fatty acids is increased following injury [2]. However, this increased demand is unlikely to require supplementation to meet it, as long as sufficient dietary intake is maintained.

Probably the fatty acids most associated with injury are the omega-3 fatty acids. These fatty acids are widely associated with anti-inflammatory and immunomodulatory properties [48]. Thus, there are wide-ranging recommendations for omega-3 supplementation during recovery from injuries. Clearly, in situations with chronic or excessive inflammation, e.g. rheumatoid arthritis, efficacy of omega-3 supplementation is apparent [48]. These fatty acids are found in high levels in the oil of many fishes, e.g. mackerel and salmon, as well as walnuts, flax seed oil and other sources. Thus, fish oil supplementation is often touted for depression of inflammation. Moreover, there is the suggestion that omega- 6 fatty acids should be avoided to enhance anti-inflammatory properties. In particular, the omega-6/omega-3 ratio should be low to enhance anti-inflammation [49]. This opinion is not universal and more recent evidence suggests that omega- 6 fatty acids also have anti-inflammatory properties [50,
51]. Thus, adequate intakes of both types of fatty acids should be encouraged. However, unless the inflammatory processes are excessive following injury - an unlikely event for most healthy exercisers - there is little reason to use supplements.

There is new evidence, albeit rather limited, to suggest that fish oil supplementation may be important for muscle loss. A recent rodent study demonstrated that fish oil supplementation may ameliorate muscle atrophy during immobilization [52]. This effect seems to be mediated by attenuation of the immobilization-disturbed mTOR signalling pathways involved in translation initiation and muscle protein synthesis. This intriguing result in rodent muscle clearly should be followed up in human studies. Figure 2 illustrates the potential efficacy of fish oil and leucine for amelioration of muscle loss.

As with carbohydrate and fat intakes, micronutrient deficiencies should also be avoided. Certainly, sufficient intake of calcium and vitamin D during healing from fractures is important for optimal bone formation. There is a clear association of micronutrients, such as zinc, vitamin $\mathrm{C}$, or vitamin $\mathrm{A}$, with various aspects of wound healing. 
For example, vitamin $\mathrm{C}$ is associated with hydroxyproline synthesis necessary for collagen formation. However, there is no clear evidence for the necessity of supranormal micronutrient intakes during recovery from injury [2].

Creatine supplementation is another interesting potential nutritional countermeasure to muscle loss. It is widely used to enhance resistance exercise-induced muscle hypertrophy [53]. Moreover, creatine has been used to counter muscle disorders [54]. Thus, the use of creatine to counter muscle loss during immobilization has been investigated. Unfortunately, the evidence in the limited number of studies to date is rather equivocal. Creatine supplementation during 2 weeks of lower-limb casting did not attenuate muscle loss in otherwise healthy volunteers [55] or in patients following total knee arthroplasty [56]. However, more recently, loss of muscle in arms immobilized for 7 days was ameliorated with creatine supplementation [57]. It is likely that the differences between studies were due to differential responses of arms and legs to immobilization. Still, more research must be done to determine the impact of creatine supplementation on muscle loss in various muscle groups.

Other nutritional considerations must come into play during immobility. Non-steroidal anti-inflammatory drugs (NSAIDS) are often recommended following injury. Whereas this recommendation makes intuitive sense, there is evidence that NSAIDS actually interfere with healing in many [58], but not all [59], circumstances. Moreover, there is evidence that nonselective NSAIDS inhibit the response of muscle protein synthesis to resistance exercise [60], but that specific COX-2 inhibitors do not [61]. Thus, the use of these drugs during immobilization should be carefully considered and perhaps even avoided [59].

Certainly, excessive alcohol intake should be avoided. Ethanol excess has been shown to exacerbate muscle loss with immobilization in rats [62]. Ethanol ingestion impairs muscle protein synthesis [63], almost certainly a major contributor to the accelerated muscle loss. Thus, excessive alcohol intake during immobility should be avoided.

\section{Stage 2: Rehabilitation and Hypertrophy}

The second phase of recovery from injury is the rehabilitation stage. The metabolic and functional situation during the rehabilitation stage is different from that during enforced inactivity of the limb. Even with active rehabilitation, the recovery of muscle size and strength often takes longer than the time in which it was lost [3].

In many cases, it is likely that the overall energy expenditure will increase, albeit, as discussed above, perhaps not as much as may be intuitively accepted. Increasing activity will restore basal levels of muscle protein synthesis $[64,65]$. Exercise increases the synthesis of muscle proteins - the type of exercise will determine the response of the particular protein types [66] - in the previously immobilized limb.

Increased synthesis of myofibrillar proteins in response to resistance exercise will lead to hypertrophy of atrophied muscles [66]. Moreover, tendon collagen synthesis is increased during rehabilitation from immobilization [67]. Since, the energy cost of muscle protein synthesis is high $[68,69]$, energy requirements will increase. Again, perhaps a bit counterintuitively, there is ample evidence that muscle protein breakdown is increased during rehabilitation-induced muscle growth, probably to improve muscle remodelling [3]. Certainly, resistance exercise increases muscle protein breakdown $[65,70]$. These increases in muscle protein turnover will contribute to increased energy requirements during recovery. So, with increased activity and metabolism, energy expenditure is almost certain to increase during rehabilitation. Clearly, since synthesis of muscle and other proteins is critical, energy intake should not be restricted much, if at all. These processes are illustrated in figure 3.

\section{Nutrition Support for Rehabilitation and Recovery from Immobilization}

Following injury-induced immobility, the primary nutritional goal will be to support muscle growth and increased strength with rehabilitation and training. For the most part, what information is available points to a nutritional strategy that would be similar for any other exerciser desiring increased muscle mass. Thus, much of the attention should be on energy and protein intake $[6,7,15$, 71-75].

Increased protein intake may support increased protein turnover, but the amount necessary may not be as high as many believe. Increased amino acid availability following exercise stimulates muscle protein synthesis resulting in positive net muscle protein balance leading to muscle hypertrophy [25]. A recent study suggested that increased protein intake enhances recovery from immobilization [76], but other results are somewhat equivocal. Future, metabolically focussed, studies could shed more light on this type of question. However, how much protein to include in the diet is still a big question mark. In 


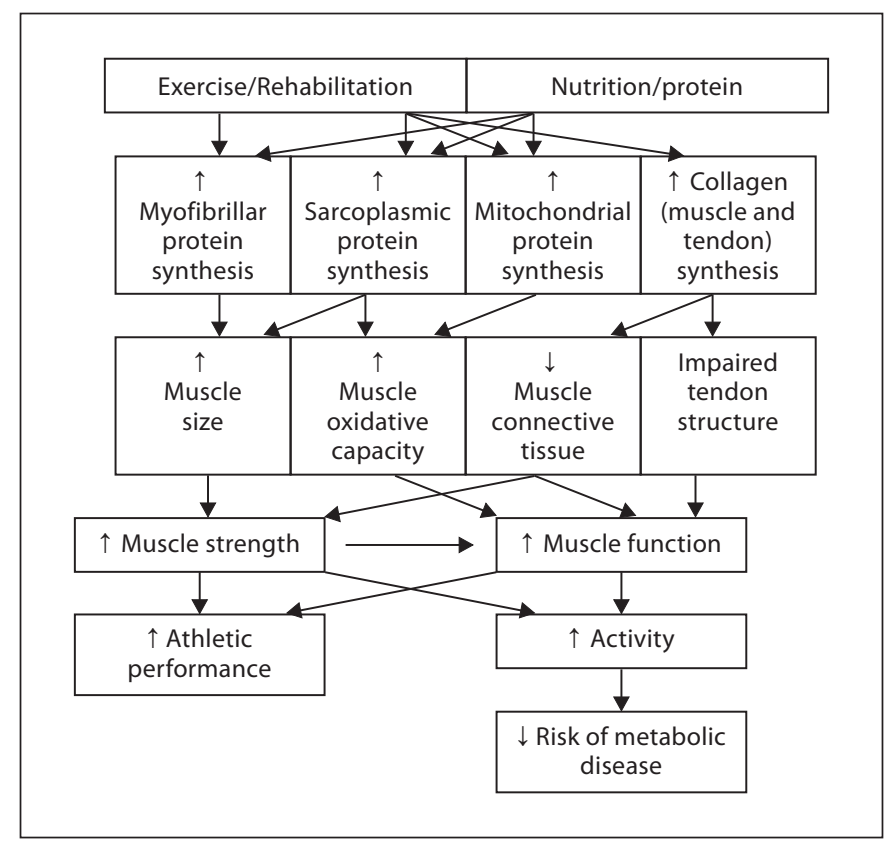

Fig. 3. Flow diagram of the metabolic and functional changes in muscle and tendon when activity is restored following immobilization due to injury. Exercise and amino acids stimulate muscle and exercise stimulates tendon synthesis, thus restoring muscle size and function. Note that the time course of the return of muscle mass and strength is often much slower than the loss during immobilization.

healthy, young males, muscle hypertrophy occurs with much less dietary protein than many believe necessary (e.g. approx. $1.2 \mathrm{~g} / \mathrm{kg} /$ day) [73]. Certainly, as long as it fits within total energy requirements and does not restrict the amount of carbohydrate or essential fat intake, then elevating protein intake may not be a problem. There seems little reason to increase protein intake with the goal of increasing tendon collagen synthesis. Neither muscle nor tendon collagen synthesis responds to provision of amino acids $[36,77]$.

It must be emphasized that the notion that dramatically increasing protein intake results in a proportional increase in muscle size and function is not supportable [7, $73,75]$. Other factors may be more important. The timing of protein intake in relation to exercise, the type of protein, other concurrently ingested nutrients and interactions between these factors all influence the utilization of the amino acids from ingested protein. Thus, the total amount of protein may not be the most important nutritional factor influencing muscle hypertrophy. A detailed examination of these factors is beyond the scope of this review, but interested readers are referred to any of these excellent reviews [6, 7, 15, 71-75].

The bulk of our discussion has focused on protein and energy. However, other nutrients are often touted as important for optimal recovery from disuse. Unfortunately, as with most factors, there is little evidence from studies directly addressing exercise-induced injury. Thus, the evidence is sparse and often equivocal. For example, in healthy, young individuals, creatine supplementation clearly resulted in enhanced recovery of muscle mass and function during 10 weeks following 2 weeks of immobilization [55]. However, creatine supplementation for 12 weeks following anterior cruciate ligament surgery did not improve muscle mass or strength [78]. It is not difficult to imagine that the injury per se, perhaps due to the inflammatory response $[1,2]$, may impact the metabolic response, thus rendering the creatine less effective following injury. Unfortunately, there do not seem to be any data on this topic. Moreover, the immobilization was much longer in the study in which creatine did not work [78]. Thus, the length of immobilization may make the muscle resistant to the anabolic impact of creatine. However, the metabolic mechanism for this difference is not easily deduced - and has certainly never been demonstrated. Thus, the jury is still out on the efficacy of creatine for recovery of muscle following disuse atrophy.

\section{Summary and Recommendations}

Clearly, the most important consideration for recovery from injury is to avoid malnutrition. During immobilization following an exercise-induced injury muscle protein synthesis is decreased. Moreover, the response of muscle to anabolic stimuli is reduced. These changes lead to increased periods of negative net muscle protein balance and as a result muscle mass is lost. Muscle and tendon function are compromised. The most important nutritional consideration is to ensure sufficient energy and protein, as well as micronutrient intakes. Energy requirements probably are reduced less than many may think. There may be little point in increasing protein intake, but there are indications that increased leucine may ameliorate muscle loss. Moreover, recent preliminary evidence suggests that omega- 3 fatty acid supplementation may help reduce muscle loss. However, more research in humans needs to be done before these recommendations can be made with certainty. Creatine supplementation may help limit muscle loss, but perhaps not in all limbs. 
Similarly, there is a suggestion that protein supplements may contribute to fracture healing, however direct evidence in healthy athletes is lacking.

During rehabilitation and recovery following immobilization, it is likely that energy needs will increase due to the restoration of physical activity and increased protein turnover. During this stage, there is a rationale to increase protein intake, but not at the expense of sufficient carbohydrate to support renewed training. Creatine supplementation may help increase the rate of muscle hypertrophy; success of creatine supplementation may depend on the type of injury and the length of immobilization.

Ultimately, a balanced diet with sufficient energy, ample carbohydrate, protein and micronutrient intakes is always the best approach. A first-do-no-harm approach to other nutrients and supplements is probably the best rec- ommendation. Careful consideration for negative repercussions of any supplement or nutrient should be made. If there is no evidence for possible consequences for a particular nutrient, then perhaps it can be tried. An underappreciated - certainly not well-studied in this context - issue may be interactions. A shotgun approach of just trying everything for which there is some evidence of efficacy could be a mistake. The best chance to optimize nutrition to enhance recovery from injury should be tempered by a fair bit of caution to avoid the risk of negative consequences.

\section{Disclosure Statement}

The author declares no conflicts of interest.

\section{References}

1 Demling RH: Nutrition, anabolism, and the wound healing process: an overview. Eplasty 2009;9:e9.

-2 Arnold M, Barbul A: Nutrition and wound healing. Plast Reconstr Surg 2006;117:42S$58 \mathrm{~S}$.

-3 Jones SW, Hill RJ, Krasney PA, O’Conner B, Peirce N, Greenhaff PL: Disuse atrophy and exercise rehabilitation in humans profoundly affects the expression of genes associated with the regulation of skeletal muscle mass. FASEB J 2004; 18:1025-1027.

-4 de Boer MD, Maganaris CN, Seynnes OR, Rennie MJ, Narici MV: Time course of muscular, neural and tendinous adaptations to 23 day unilateral lower-limb suspension in young men. J Physiol 2007;583:1079-1091.

5 Phillips S: Protein requirements and supplementation in strength sports. Nutrition 2004;20:689-695.

-6 Tipton KD, Jeukendrup AE, Hespel P: Nutrition for the sprinter. J Sports Sci 2007;25(suppl 1):S5-S15.

-7 Tipton KD, Wolfe RR: Protein and amino acids for athletes. J Sports Sci 2004;22:65-79.

8 Lorenz HP, Longaker MT: Wounds: biology, pathology, and management; in Norton JA, Barie PS, Bollinger RR, Chang AE, Lowry SF, Mulvhill SJ, Pass HI, Thompson RW (eds): Surgery: Basic Science and Clinical Evidence. New York, Spring Publishing Company, 2008, pp 191-208.

$\checkmark 9$ Lin E, Kotani JG, Lowry SF: Nutritional modulation of immunity and the inflammatory response. Nutrition 1998;14:545-550.

-10 Barnes GL, Kostenuik PJ, Gerstenfeld LC, Einhorn TA: Growth factor regulation of fracture repair. J Bone Miner Res 1999;14: 1805-1815.
Stechmiller JK: Understanding the role of nutrition and wound healing. Nutr Clin Pract 2010;25:61-68.

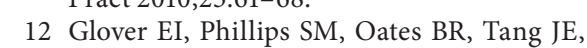
Tarnopolsky MA, Selby A, Smith K, Rennie MJ: Immobilization induces anabolic resistance in human myofibrillar protein synthesis with low and high dose amino acid infusion. J Physiol 2008;586:6049-6061.

13 Phillips SM, Glover EI, Rennie MJ: Alterations of protein turnover underlying disuse atrophy in human skeletal muscle. J Appl Physiol 2009;107:645-654.

14 Ferrando AA, Lane HW, Stuart CA, DavisStreet J, Wolfe RR: Prolonged bed rest decreases skeletal muscle and whole body protein synthesis. Am J Physiol 1996;270:E627E633.

15 Rennie MJ, Selby A, Atherton P, Smith K, Kumar V, Glover EL, Philips SM: Facts, noise and wishful thinking: muscle protein turnover in aging and human disuse atrophy. Scand J Med Sci Sports 2010;20:5-9.

16 Abadi A, Glover EI, Isfort RJ, Raha S, Safdar A, Yasuda N, Kaczor JJ, Melov S, Hubbard A, Qu X, Phillips SM, Tarnopolsky M: Limb immobilization induces a coordinate downregulation of mitochondrial and other metabolic pathways in men and women. PLoS One 2009;4:e6518.

17 Richter EA, Kiens B, Mizuno M, Strange S: Insulin action in human thighs after onelegged immobilization. J Appl Physiol 1989; 67:19-23.

18 Stuart CA, Shangraw RE, Prince MJ, Peters EJ, Wolfe RR: Bed-rest-induced insulin resistance occurs primarily in muscle. Metabolism 1988;37:802-806.
19 Op 't Eijnde B, Urso B, Richter EA, Greenhaff PL, Hespel P: Effect of oral creatine supplementation on human muscle glut 4 protein content after immobilization. Diabetes 2001; 50:18-23.

20 Wilkes EA, Selby AL, Atherton PJ, Patel R, Rankin D, Smith K, Rennie MJ: Blunting of insulin inhibition of proteolysis in legs of older subjects may contribute to age-related sarcopenia. Am J Clin Nutr 2009;90:13431350.

21 Rasmussen BB, Fujita S, Wolfe RR, Mittendorfer B, Roy M, Rowe VL, Volpi E: Insulin resistance of muscle protein metabolism in aging. FASEB J 2006;20:768-769.

22 Wilkinson SB, Tarnopolsky MA, Macdonald MJ, Macdonald JR, Armstrong D, Phillips SM: Consumption of fluid skim milk promotes greater muscle protein accretion after resistance exercise than does consumption of an isonitrogenous and isoenergetic soyprotein beverage. Am J Clin Nutr 2007;85: 1031-1040.

-23 Tipton KD, Ferrando AA, Phillips SM, Doyle D Jr, Wolfe RR: Postexercise net protein synthesis in human muscle from orally administered amino acids. Am J Physiol 1999; 276:E628-E634.

24 Tang JE, Moore DR, Kujbida GW, Tarnopolsky MA, Phillips SM: Ingestion of whey hydrolysate, casein, or soy protein isolate: effects on mixed muscle protein synthesis at rest and following resistance exercise in young men. J Appl Physiol 2009;107:987992.

25 Biolo G, Tipton KD, Klein S, Wolfe RR: An abundant supply of amino acids enhances the metabolic effect of exercise on muscle protein. Am J Physiol 1997;273:E122-E129. 
26 Anthony JC, Anthony TG, Layman DK: Leucine supplementation enhances skeletal muscle recovery in rats following exercise. J Nutr 1999;129:1102-1106.

-27 Kimball SR, Jefferson LS: Regulation of global and specific mRNA translation by oral administration of branched-chain amino acids. Biochem Biophys Res Commun 2004; 313:423-427.

28 Kimball SR, Jefferson LS: Role of amino acids in the translational control of protein synthesis in mammals. Semin Cell Dev Biol 2005; 16:21-27.

-29 Koopman R: Combined ingestion of protein and carbohydrate improves protein balance during ultra-endurance exercise. Am J Physiol Endocrinol Metab 2004;287:E712E720.

- 30 Koopman R, Verdijk LB, Beelen M, Gorselink M, Kruseman AN, Wagenmakers AJM, Kuipers H, van Loon LJC: Co-ingestion of leucine with protein does not further augment post-exercise muscle protein synthesis rates in elderly men. Br J Nutr 2008;99:571580.

- 31 Tipton KD, Elliott TA, Ferrando AA, Aarsland AA, Wolfe RR: Stimulation of muscle anabolism by resistance exercise and ingestion of leucine plus protein. Appl Physiol Nutr Metab 2009;34:151-161.

- 32 Baptista IL, Leal ML, Artioli GG, Aoki MS, Fiamoncini J, Turri AO, Curi R, Miyabara EH, Moriscot AS: Leucine attenuates skeletal muscle wasting via inhibition of ubiquitin ligases. Muscle Nerve 2010;41:800-808.

- 33 Cuthbertson D, Smith K, Babraj J, Leese G, Waddell T, Atherton P, Wackerhage H, Taylor PM, Rennie MJ: Anabolic signaling deficits underlie amino acid resistance of wasting, aging muscle. FASEB J 2005;19:422424.

-34 Katsanos CS, Kobayashi H, Sheffield-Moore M, Aarsland A, Wolfe RR: A high proportion of leucine is required for optimal stimulation of the rate of muscle protein synthesis by essential amino acids in the elderly. Am J Physiol Endocrinol Metab 2006;291:E381E387.

-35 Rieu I: Leucine supplementation improves muscle protein synthesis in elderly men independently of hyperaminoacidaemia. J Physiol 2006;575:305-315.

36 Babraj JA, Cuthbertson DJ, Smith K, Langberg H, Miller B, Krogsgaard MR, Kjaer M, Rennie MJ: Collagen synthesis in human musculoskeletal tissues and skin. Am J Physiol Endocrinol Metab 2005;289:E864E869.

- 37 Babraj JA, Smith K, Cuthbertson DJ, Rickhuss P, Dorling JS, Rennie MJ: Human bone collagen synthesis is a rapid, nutritionally modulated process. J Bone Miner Res 2005; 20:930-937.

-38 Delmi M, Rapin CH, Bengoa JM, Delmas PD, Vasey H, Bonjour JP: Dietary supplementation in elderly patients with fractured neck of the femur. Lancet 1990;335:1013-1016.
39 Eneroth M, Olsson UB, Thorngren KG: Nutritional supplementation decreases hip fracture-related complications. Clin Orthop Relat Res 2006;451:212-217.

40 Schurch MA, Rizzoli R, Slosman D, Vadas L, Vergnaud P, Bonjour JP: Protein supplements increase serum insulin-like growth factor-I levels and attenuate proximal femur bone loss in patients with recent hip fracture. A randomized, double-blind, placebo-controlled trial. Ann Intern Med 1998;128:801809.

41 Waters RL, Campbell J, Perry J: Energy cost of three-point crutch ambulation in fracture patients. J Orthop Trauma 1987;1:170-173.

42 McBeath AA, Bahrke M, Balke B: Efficiency of assisted ambulation determined by oxygen consumption measurement. J Bone Joint Surg Am 1974;56:994-1000.

43 Frankenfield D: Energy expenditure and protein requirements after traumatic injury. Nutr Clin Pract 2006;21:430-437.

44 Wolfe RR: The underappreciated role of muscle in health and disease. Am J Clin Nutr 2006;84:475-482.

45 Pasiakos SM, Vislocky LM, Carbone JW, Altieri N, Konopelski K, Freake HC, Anderson JM, Ferrando AA, Wolfe RR, Rodriguez NR: Acute energy deprivation affects skeletal muscle protein synthesis and associated intracellular signaling proteins in physically active adults. J Nutr 2010;140:745-751.

46 Churchley EG, Coffey VG, Pedersen DJ, Shield A, Carey KA, Cameron-Smith D, Hawley JA: Influence of preexercise muscle glycogen content on transcriptional activity of metabolic and myogenic genes in welltrained humans. J Appl Physiol 2007;102: 1604-1611.

-47 Howarth KR, Phillips SM, Macdonald MJ, Richards D, Moreau NA, Gibala MJ: Effect of glycogen availability on human skeletal muscle protein turnover during exercise and recovery. J Appl Physiol 2010;109:431-438.

48 Galli C, Calder PC: Effects of fat and fatty acid intake on inflammatory and immune responses: a critical review. Ann Nutr Metab 2009;55:123-139.

49 Simopoulos AP, Leaf A, Salem N Jr: Essentiality of and recommended dietary intakes for omega- 6 and omega-3 fatty acids. Ann Nutr Metab 1999;43:127-130.

50 Calder PC, Yaqoob P: Understanding omega-3 polyunsaturated fatty acids. Postgrad Med 2009;121:148-157.

51 Calder PC, Deckelbaum RJ: Omega-3 fatty acids: time to get the messages right! Curr Opin Clin Nutr Metab Care 2008;11:91-93.

52 You JS, Park MN, Song W, Lee YS: Dietary fish oil alleviates soleus atrophy during immobilization in association with Akt signaling to $\mathrm{p} 70 \mathrm{~s} 6 \mathrm{k}$ and $\mathrm{E} 3$ ubiquitin ligases in rats. Appl Physiol Nutr Metab 2010;35:310-318.

53 Hespel P, Derave W: Ergogenic effects of creatine in sports and rehabilitation. Subcell Biochem 2007;46:245-259.
4 Tarnopolsky MA: Clinical use of creatine in neuromuscular and neurometabolic disorders. Subcell Biochem 2007;46:183-204.

- 55 Hespel P, Op’t Eijnde B, Van Leemputte M, Urso B, Greenhaff PL, Labarque V, Dymarkowski S, Van Hecke P, Richter EA: Oral creatine supplementation facilitates the rehabilitation of disuse atrophy and alters the expression of muscle myogenic factors in humans. J Physiol 2001;536:625-633.

56 Roy BD, de Beer J, Harvey D, Tarnopolsky MA: Creatine monohydrate supplementation does not improve functional recovery after total knee arthroplasty. Arch Phys Med Rehabil 2005;86:1293-1298.

- 57 Johnston AP, Burke DG, MacNeil LG, Candow DG: Effect of creatine supplementation during cast-induced immobilization on the preservation of muscle mass, strength, and endurance. J Strength Cond Res 2009;23: 116-120.

-58 Ferry ST, Dahners LE, Afshari HM, Weinhold PS: The effects of common anti-inflammatory drugs on the healing rat patellar tendon. Am J Sports Med 2007;35:1326-1333.

59 Mehallo CJ, Drezner JA, Bytomski JR: Practical management: nonsteroidal antiinflammatory drug (NSAID) use in athletic injuries. Clin J Sport Med 2006;16:170-174.

60 Trappe TA, White F, Lambert CP, Cesar D, Hellerstein M, Evans WJ: Effect of ibuprofen and acetaminophen on postexercise muscle protein synthesis. Am J Physiol Endocrinol Metab 2002;282:E551-E556.

61 Burd NA, Dickinson JM, Lemoine JK, Carroll CC, Sullivan BE, Haus JM, Jemiolo B, Trappe SW, Hughes GM, Sanders CE Jr, Trappe TA: Effect of a cyclooxygenase-2 inhibitor on postexercise muscle protein synthesis in humans. Am J Physiol Endocrinol Metab 2010;298:E354-E361.

62 Vargas R, Lang CH: Alcohol accelerates loss of muscle and impairs recovery of muscle mass resulting from disuse atrophy. Alcohol Clin Exp Res 2008;32:128-137.

63 Lang CH, Frost RA, Kumar V, Wu D, Vary TC: Impaired protein synthesis induced by acute alcohol intoxication is associated with changes in eIF4E in muscle and eIF2B in liver. Alcohol Clin Exp Res 2000;24:322-331.

64 Phillips SM, Parise G, Roy BD, Tipton KD, Wolfe RR, Tamopolsky MA: Resistancetraining-induced adaptations in skeletal muscle protein turnover in the fed state. Can J Physiol Pharmacol 2002;80:1045-1053.

65 Phillips SM, Tipton KD, Ferrando AA, Wolfe $\mathrm{RR}$ : Resistance training reduces the acute exercise-induced increase in muscle protein turnover. Am J Physiol 1999;276:E118-E124.

66 Wilkinson SB, Phillips SM, Atherton PJ, Patel R, Yarasheski KE, Tarnopolsky MA, Rennie MJ: Differential effects of resistance and endurance exercise in the fed state on signalling molecule phosphorylation and protein synthesis in human muscle. J Physiol 2008; 586:3701-3717. 
67 Christensen B, Dyrberg E, Aagaard P, Kjaer M, Langberg H: Short-term immobilization and recovery affect skeletal muscle but not collagen tissue turnover in humans. J Appl Physiol 2008;105:1845-1851.

-68 Giordano M, Castellino P: Correlation between amino acid induced changes in energy expenditure and protein metabolism in humans. Nutrition 1997;13:309-312.

69 Waterlow JC, Garlick PJ, Millward DJ: Protein Turnover in Mammalian Tissues and in the Whole Body. Amsterdam, North Holland Publishing Co, 1978.

70 Biolo G, Maggi SP, Williams BD, Tipton KD Wolfe RR: Increased rates of muscle protein turnover and amino acid transport after resistance exercise in humans. Am J Physiol 1995;268:E514-E520.
71 Burd NA, Tang JE, Moore DR, Phillips SM: Exercise training and protein metabolism: influences of contraction, protein intake, and sex-based differences. J Appl Physiol 2008;106:1692-1701.

72 Little JP, Phillips SM: Resistance exercise and nutrition to counteract muscle wasting. Appl Physiol Nutr Metab 2009;34:817-828.

73 Phillips SM: Physiologic and molecular bases of muscle hypertrophy and atrophy: impact of resistance exercise on human skeletal muscle (protein and exercise dose effects). Appl Physiol Nutr Metab 2009;34:403-410.

74 Tipton KD, Ferrando AA: Improving muscle mass: response of muscle metabolism to exercise, nutrition and anabolic agents. Essays Biochem 2008;44:85-98.

75 Tipton KD, Witard OC: Protein requirements and recommendations for athletes: relevance of ivory tower arguments for practical recommendations. Clin Sports Med 2007;26:17-36.
6 Holm L, Esmarck B, Mizuno M, Hansen H, Suetta C, Holmich P, Krogsgaard M, Kjaer $\mathrm{M}$ : The effect of protein and carbohydrate supplementation on strength training outcome of rehabilitation in ACL patients. J Orthop Res 2006;24:2114-2123.

77 Holm L, van Hall G, Rose AJ, Miller BF, Doessing S, Richter EA, Kjaer M: Contraction intensity and feeding affect collagen and myofibrillar protein synthesis rates differently in human skeletal muscle. Am J Physiol Endocrinol Metab 2010;298:E257-E269.

78 Tyler TF, Nicholas SJ, Hershman EB, Glace BW, Mullaney MJ, McHugh MP: The effect of creatine supplementation on strength recovery after anterior cruciate ligament (ACL) reconstruction: a randomized, placebo-controlled, double-blind trial. Am J Sports Med 2004;32:383-388. 